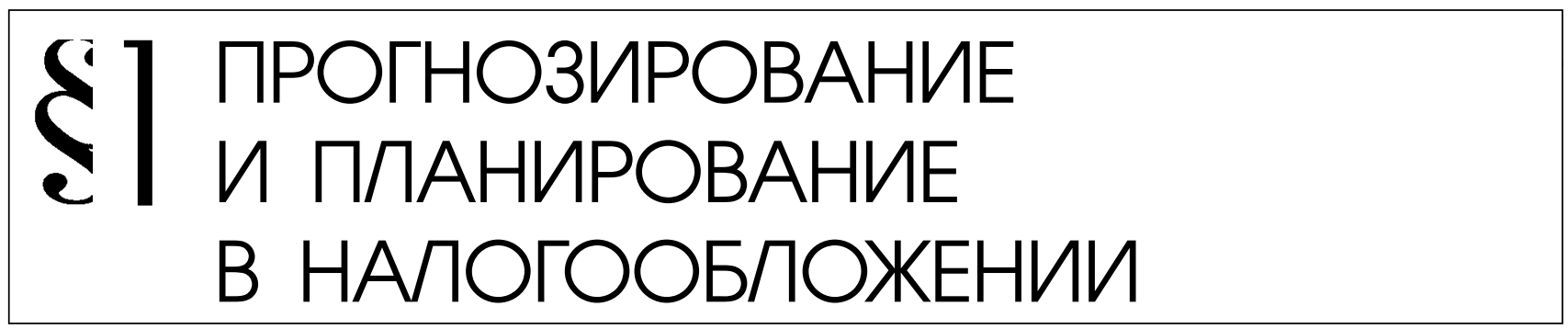

К.Р. Гаджиева

\title{
РОЛЬ СЕЛЬСКОГО ХОЗЯЙСТВА В НАЛОГОВОМ ПОТЕНЦИАЛЕ РЕГИОНА (НА МАТЕРИАЛАХ РЕСПУБЛИКИ ДАГЕСТАН)
}

Аннотация: в статье исследуется налоговый потенциал региона как отражение экономического потенциала. Прослеживается их тесная взаимосвязь. В работе даются различные определения налогового потенциала. Дается общий обзор налогового потенциала по региону, в том числе по доначислениям. А также анализируется на статистических данных УФНС по республике Дагестан какую долю составляют налоговый платежи от сельскохозяйственной деятельности, раскрывая важность данной отрасли в развитии экономики региона. Дана структура по категориям хозяйств, то есть субъектов налогообложения по производству в растениеводстве. Прослеживается важность единого сельскохозяйственного налога как специального режима налогообложения для сельхозпроизводителей. Представлены в табличной форме начисления в консолидированный бюджет РФ по данному налогу в работе проводится анализ налогового потенциала, с применением теоретического и практического материалов. Исследуется взаимосвязь двух понятий налогового и экономического потенциала. Ряд данных представлены в табличной форме с анализом и выводом. Статья может представить теоретический и практический интерес. Проводится глубокий анализ возможности повышения налогового потенциала региона, раскрыв вопрос приоритета в отраслевом развитии и возможности интенсивного роста налоговых платежей регионального бюджета. Сделаны выводы о роли сельского хозяйства в повышении экономического потенциала региона. В том числе о причинах низких показателей по платежа сельхозпроизводителей в бюджет, в том числе по ЕСХН.

Ключевые слова: сельское хозяйство, сельхозпроизводители, налоговый потенциал, экономический потенциал, инвестиционная активность, единый сельскохозяйственный налог, региональный бюджет, интенсивное развитие, категории хозяйств, отраслевая структура.

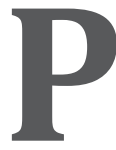

азвитие государства начинается с преобразования каждого его отдельного региона. Региональный бюджет играет большую роль в эффективном функционировании налоговой политики всего государства, так как ориентир на самостоятельность бюджета выявляет дополнительные финансы для осуществления государственных программ в области развития экономики. Планирование налоговых платежей исходит из оценки налогового потенциала на очередной финансовый год или на долгосрочный период, что в свою очередь опирается на экономический потенциал.

Известно, что в российской экономике присутствует диспропорция в объеме денег и ее развитием. Так по источникам 
первый показатель в отдельные годы вырос на 50\% при экономическом росте $8 \%$. Денежная масса обусловлена продажей нефти и энергоресурсов. И в тоже время реальный сектор экономики развивается слабо, в основном это - торговля, недвижимость, строительство. В тоже время идет рост импорта, что привело к тотальному заполнению рынков зарубежными продуктами питания и другими различными товарами. Тенденция замещения местными продуктами питания на импортные даже наблюдается в республике Дагестан, где исторически сложилась культура ведения домашнего хозяйства.

Необходимо обратить внимание на реальный сектор экономики и развивать его параллельно с введением инноваций в экономику государства.

Опыт ведения сельского хозяйства и трудовой потенциал говорят о том, что экономический потенциал данной отрасли используется на очень низком уровне. Однако возможности его достаточны для того, чтобы являться базой для роста экономического, а впоследствии налогового потенциала.

Экономика горных территорий в настоящее время характеризуется сильно выраженной сельскохозяйственной специализацией, низким притоком инвестиций в основной капитал, слаборазвитой торговлей и утраченными функциями промышленности. В общем объеме продукции сельского хозяйства по республике, доля горных территорий составляет 43\%; инвестиций в основной капитал $-7 \%$; розничного товарооборота -7,5\%; отгруженных промышленных товаров $-10,7 \%{ }^{1}$.

\footnotetext{
Юсуфов Р. А. Об утверждении Республиканской целевой программы «Социально-экономическое развитие горных территорий Республики Дагестан на 2014-2018 годы». htt//www.mcxrd.ru/
}

Итоги социально-экономического развития Республики Дагестан за 2013 года характеризуется позитивными тенденциями с ростом темпов основных макроэкономических показателей.

Положительная динамика роста по сравнению с 2012 годом отмечена в промышленности $(137,5 \%)$, сельском хозяйстве $(106,4 \%)$, налоговые и неналоговые доходы консолидированного бюджета республики увеличились на $16 \%$.

В результате более благоприятных агроклиматических условий прошедшего года и достигнутых высоких показателей урожайности объем продукции сельского хозяйства составил более 77 млрд. руб. (на 6,4\% больше уровня 2012 года). Таким образом, растениеводство еще сильно зависит от природных условий, тогда как в зарубежных странах такая зависимость не столь велика.

Взаимосвязь экономического и налогового потенциала неизбежно ведет к тому, что необходимо поднимать наиболее перспективные отрасли для каждого региона конкретно. Как известно, на уровень налогового потенциала влияют различные факторы, среди них можно выделить:

- уровень безработицы;

- динамика и уровень цен;

- количество крупных производств;

- отраслевая структура;

- экономическое развитие.

В консолидированный бюджет Республики Дагестан за 2013 год поступило 19,2 млрд. рублей с приростом на Змлрд. рублей или на 18,7 \% (по СКФО прирост - 13,1 \%, по России - 2,9 \%). Индикативные показатели доходов федерального бюджета выполнены на 100,1 \% (ИПП - 3 746,6 млн. рублей, исполнено 3 750,4 млн. рублей). Бюджетные назначения доходов консолидированного бюджета РД выполнены на 103,0 \% (бюджетные назначения - 19,4 
млрд. рублей, исполнено - 20,0 млрд. рублей), сверх плана республика дополнительно получила 600 млн. рублей. Приоритеты инвестиционной политики Дагестана ориентированы на раскрытие естественных преимуществ республики, главным из которых является огромный потенциал в сфере сельского хозяйства. Дагестан занимает второе место в России по численности крупного рогатого скота, третье по площадям многолетних насаждений и производству винограда. Доля агропромышленного комплекса в ВВП республики составляет более $15 \%$, а численность занятых в отрасли $-27 \%$.

На сегодняшний день более $80 \%$ валовой продукции дагестанского АПК приходится на небольшие частные хозяйства. Однако невысокий уровень агротехники и агрокультуры в этой структуре сельхозпроизводства не позволяет решать хронические проблемы отрасли: низкая урожайность, высокая себестоимость производства, слабая материально-техническая база, низкий уровень инвестиционной активности в сельском хозяйстве.

Все эти условия способствуют тому, что данная отрасль не может в полной мере проявить свой экономический потенциал, а впоследствии и налоговый. Доля поступлений по налоговым платежам, составляющим основные взносы от сельхозпроизводителей, в консолидированный бюджет Дагестана (РД) должна быть выше.

Самым значимым по своему функциональному значению является единый сельскохозяйственный налог, который должен играть стимулирующую и регулирующую роль. Это специальный налоговый режим, который разработан и введен специально для производителей сельскохозяйственной продукции, который освобождает от налогов для организации:
- налога на прибыль организаций (за исключением налога, уплачиваемого с доходов по дивидендам и отдельным видам долговых обязательств),

- налога на имущество организаций,

- налога на добавленную стоимость (за исключением НДС, уплачиваемого при ввозе товаров на таможне, а также при выполнении договора простого товарищества или договора доверительного управления имуществом).

Для индивидуальных предпринимателей:

- налога на доходы физических лиц (в отношении доходов от предпринимательской деятельности),

- налога на имущество физических лиц (по имуществу, используемому в предпринимательской деятельности),

- налога на добавленную стоимость (за исключением НДС, уплачиваемого при ввозе товаров на таможне, а также при выполнении договора простого товарищества или договора доверительного управления имуществом).

В следующей таблице представим структуру начислений и налоговую базу по ЕСХН по РД по итогам 2012 года (таблица 1).

Из данной таблицы видно, что сумма убытков по ЕСХН, понижающая налоговую базу образует значительную долю, что ведет к уменьшению его суммы. Что говорит о том, что сельхозпроизводители несут большие убытки.

Производство в сельском хозяйстве остается затратной.

За период с 2003 по 2014 годы Республиканской межведомственной комиссией по финансовому оздоровлению сельхозтоваропроизводителей были приняты решения реструктуризировать задолженность по 544 сельхозпредприятиям, в результате чего списано более 278 миллионов рублей. 
Налоговая база и структура начислений по единому сельскохозяйственному налогу, в тыс. руб.

\begin{tabular}{|l|c|c|c|}
\hline \multicolumn{1}{|c|}{ Наименование показателей } & \multicolumn{2}{|c|}{ Значения показателей } \\
\cline { 2 - 4 } & Всего & $\begin{array}{c}\text { вом числе } \\
\text { организа- } \\
\text { ции }\end{array}$ & $\begin{array}{c}\text { индивидуальные } \\
\text { предприниматели } \\
\text { и крестьянские (фер- } \\
\text { мерские) хозяйства }\end{array}$ \\
\hline Сумма доходов (тыс.руб.) & & 2840932 & 865217 \\
\hline Сумма расходов (тыс.руб.) & 3679531 & 2838262 & 841269 \\
\hline Налоговая база (тыс.руб.) & 197441 & 140414 & 57027 \\
\hline $\begin{array}{l}\text { Сумма убытка, полученного в предыдущем } \\
\text { (предыдущих) налоговом (налоговых) пе- } \\
\text { риоде (периодах), уменьшающая налоговую } \\
\text { базу за налоговый период (тыс.руб.) }\end{array}$ & 18841 & 16464 & 2377 \\
\hline $\begin{array}{l}\text { Сумма исчисленного единого сельскохозяй- } \\
\text { ственного налога (тыс.руб.) }\end{array}$ & 10716 & 7437 & 3279 \\
\hline $\begin{array}{l}\text { Количество налогоплательщиков, предста- } \\
\text { вивших налоговые декларации по единому } \\
\text { сельскохозяйственному налогу (ед./чел.) }\end{array}$ & 2235 & 1100 & \\
\hline Контрольная сумма & 7614913 & 5844609 & 135 \\
\hline
\end{tabular}

Источник: УФНС РД htt//www. nalog.ru/rn05/

Принятые меры помогли уберечь сельскохозяйственные предприятия от банкротства. Благодаря реструктуризации, предприятия получили отсрочку на 5-7 лет, рассрочку платежей - на 4-5 лет по недоимкам, в зависимости от группы финансовой устойчивости на момент подачи документов для участия в программе финансового оздоровления.

Столь незначительные поступления по ЕСХН в республике Дагестан демонстрирует низкую прибыльность, неплатежеспособность и экономическую отсталость в сфере сельского хозяйства. Несмотря на высокий природный, климатический и трудовой потенциал данная сфера «производства» находится в застое.

Также сельхозпроизводители могут выбрать и общий режим налогообложения. В следующей таблице представим ос- 
тря на то, что доля от поступлений по налогам, предусмотренным специальными налоговыми режимами, в обще сумме достаточна высокая. Так как по специальным налоговым режимам преобладает единый налог на вмененный доход и упрощенная система налогообложения (торговля).

Таблица 2.

\section{Начисление и поступление налогов и сборов в консолидированный бюджет Российской Федерации по сельскому хозяйству и охоте (на материалах р. Дагестан)}

\begin{tabular}{|l|c|}
\hline \multicolumn{1}{|c|}{ налоги } & $\mathbf{2 0 1 3}$ год \\
\hline налог на прибыль организаций & 6643 \\
\cline { 2 - 2 } в том числе в федеральный бюджет & 703 \\
\hline налог на доходы физических лиц & 37406 \\
\hline налог на добавленную стоимость & 14550 \\
\hline акцизы по подакцизным товарам & 1937 \\
\hline $\begin{array}{l}\text { остальные федеральные налоги } \\
\text { и сборы }\end{array}$ & 1340 \\
\hline налог на имущество организаций & 3264 \\
\hline транспортный налог & 4098 \\
\hline местные налоги и сборы & 26280 \\
\hline $\begin{array}{l}\text { налоги, предусмотренные специ- } \\
\text { альными налоговыми режимами }\end{array}$ & 30393 \\
\hline всего & 125911 \\
\hline
\end{tabular}

На сегодняшний момент бюджет региона недополучает налоговые доходы от экономической деятельности в сфере сельского хозяйства. Так как еще исторически сложилось, что сельское хозяйство занимает важное место среди других отраслей экономики. Об этом говорит и наличие обширных сельскохозяйственных угодий. На 2013 год в хозяйствах всех категорий площадь пашни составляет 522,1 тыс.га. Среди сельхозпроизводителей большую долю занимают хозяйства населения или фермерские хозяйства. На 2011 год их доля в структуре продукции сельского хозяйства по категориям хозяйств в растениеводстве составляет 77,1\% и 10,5\% соответственно. То есть крупных налогоплательщиков всего составляет 12,4\%. Немало мелких производителей реализуют свой товар из рук в руки, не ведут никакой отчетности, не регистрируют свои хозяйства в органах местного самоуправления. И как следствие не платят налоги.

Таким образом, роль сельского хозяйства в росте налогового потенциала значима, и может способствовать выводу региона от дотационного положения. Это и дополнительные рабочие места.

Хочется представить вашему вниманию следующее определение: налоговый потенциал - это максимально возможные налоговые ресурсы, исчисленные в условиях полной реализации положений налогового законодательства, которыми может располагать бюджетная система в целях обеспечения расширенного воспроизводства и социального развития общества. ${ }^{2}$

Это понятие особенно проявляется в сельском хозяйстве, потому как эта отрасль экономики несет все понятия представленные в данном определении. В том числе в растениеводстве, где роль расширенного воспроизводства трудно переоценить. Поэтому можно утверждать, что налоги как действенный финансовый регулятор экономики государства могут влиять на трансформации, происходящие в сельском хозяйстве. И в то же время налоговый потенциал ориентирован на возможности региона в экономическом развитии.

В настоящий период сельское хозяйство находится в не лучшем варианте. И

\footnotetext{
2 Пылаева А.В., научный руководитель АНО «Институт развития территории», координатор проекта «Разработка и тестирование системы кадастровой оценки объектов недвижимости», htt//www.irt.su.ru
} 
в то же время с вступлением в ВТО несомненно необходимо принимать срочные мере в его развитии.

Рассмотрев роль сельского хозяйства в налоговом потенциале региона, можно увидеть, что большую ценность оно представляет в повышении уровня поступлений по упрощенной системе налогообложения (УСН), единому сельскохозяйственному налогу, налогу на добавленную стоимость, НДФЛ и т.д. Это основные платежи, которые составляют налоговые обязательства налогоплательщиков в данной сфере экономической деятельности.

Таким образом, нельзя говорить какую роль играет сельское хозяйство в налоговом потенциале республики Дагестан только по фактическим налоговым поступлениям в бюджет. На самом деле доля сельского хозяйства в отраслевой структуре республики составляет на уровне 30\%, поэтому налоговый потенциал высок. Наблюдается высокий трудовой, сырьевой, земельный фонд республики, при интенсивном использовании которых возможно постепенное восстановление данной отрасли. Важным условием для экономического развития является эффективная налоговая система, контроль над осуществлением государственных программ, инвестиционная активность региона.

\section{Библиография:}

1. Налоговый кодекс Российской Федерации. М Издательство «Омега - Л», 2014.

2. Правительство республики Дагестан Постановление от 28 сентября 2012 г. 325 «О прогнозе социально-экономического развития Республики Дагестан на 2013 год и плановый период 2014 и 2015 годов».

3. Министерство сельского хозяйства Республики Дагестан Сельское хозяйство Дагестана// статистический сборник. Отпечатано 000 «Дагпресс-Медиа», 2012 г.

4. Буздалов И. Об интенсификации российского сельского хозяйства//Вопросы экономики №12-2013, с. 141-152.

5. Оробинская И.В. Методические рекомендации по оптимизации налогообложения горизонтально-интегрированных объединений АПК//Налоги и налогообложение №10-2013, с. 30-41.

6. Форма №5-ЕСХН Утверждена приказом ФНС Россииот 02.11.2012 № ММВ-71/828@ URL:htt//www. nalog.ru/rn05/

7. Пылаева A.В., научный руководитель АНО «Институт развития территории», координатор проекта «Разработка и тестирование системы кадастровой оценки объектов недвижимости», 2013. URL:htt//www.irt.su.ru

8. Юсуфов Р. А. Об утверждении Республиканской целевой программы «Социально-экономическое развитие горных территорий Республики Дагестан на 2014-2018 годы». URL: htt//www.mcxrd.ru/

\section{References:}

1. Nalogovyi kodeks Rossiiskoi Federatsii. M Izdatel’stvo «Omega — L», 2014.

2. Pravitel'stvo respubliki Dagestan Postanovlenie ot 28 sentyabrya 2012 g. 325» 0 prognoze 
DOI: $10.7256 / 1812-8688.2014 .6 .12101$

При цитировании этой статьи сноска на doi обязательна

Прогнозирование и планирование в налогообложении

sotsial'no-ekonomicheskogo razvitiya Respubliki Dagestan na 2013 god i planovyi period 2014 i 2015 godov».

3. Ministerstvo sel'skogo khozyaistva Respubliki Dagestan Sel'skoe khozyaistvo Dagestana// statisticheskii sbornik. Otpechatano 000 «Dagpress-Media», 2012g.

4. Buzdalov I. Ob intensifikatsii rossiiskogo sel'skogo khozyaistva//Voprosy ekonomiki №122013, s. 141-152.

5. Orobinskaya I.V. Metodicheskie rekomendatsii po optimizatsii nalogooblozheniya gorizontal'no-integrirovannykh ob"edinenii APK//Nalogi i nalogooblozhenie №10-2013, s. $30-41$.

6. Forma №5-ESKhN Utverzhdena prikazom FNS Rossiiot 02.11.2012 № MMV-71/828@ URL:htt//www. nalog.ru/rn05/

7. Pylaeva A.V., nauchnyi rukovoditel' ANO «Institut razvitiya territorii», koordinator proekta «Razrabotka i testirovanie sistemy kadastrovoi otsenki ob"ektov nedvizhimosti», 2013. URL:htt//www.irt.su.ru

8. Yusufov R. A. Ob utverzhdenii Respublikanskoi tselevoi programmy «Sotsial'noekonomicheskoe razvitie gornykh territorii Respubliki Dagestan na 2014-2018 gody». URL: htt//www.mcxrd.ru/ 